\title{
ASSESSMENT OF THE CHALLENGES EXPERIENCED BY NURSES CARING FOR PATIENTS DIAGNOSED WITH PSYCHOTIC DISORDERS IN NEURO- PSYCHIATRIC HOSPITALS, FROM SOUTH-WEST, NIGERIA
}

\author{
Adegbaju Funso M. and Prof. J.O Aina
}

School of Nursing, Babcock University, Ilisan, Ogun State, Nigeria.

Email: misifunsho1@gmail.com

\section{Cite this article:}

Adegbaju F.M., Aina J.O (2021), Assessment of the Challenges Experienced by Nurses Caring for Patients Diagnosed with Psychotic Disorders in Neuro-

Psychiatric Hospitals, from South-West, Nigeria. African Journal of Health, Nursing and Midwifery 4(5), 49-58. DOI: 10.52589/AJHNM-

W3PYVG78.

\section{Manuscript History}

Received: 9 July 2021

Accepted: 4 Aug 2021

Published: 17 Aug 2021

Copyright $\odot 2020$ The Author(s). This is an Open Access article distributed under the terms of Creative Commons AttributionNonCommercial-NoDerivatives 4.0 International (CC BY-NC-ND 4.0 ), which permits anyone to share, use, reproduce and redistribute in any medium, provided the original author and source are credited.
ABSTRACT: These challenges are personal, and relationships. The goal of this study was therefore to identify the challenges faced by the nurses. The study adopted quantitative research design using descriptive methods. The sample size was determined by using the Cochran formula. A self-structured questionnaire was used to collect the data from the respondents. The findings on personal challenge revealed that 423 (95.9\%) of the respondents have sufficient willingness to care, 374 (84.8\%) revealed that respondents have emotional intelligence, 405 $(91.8 \%)$ claimed they are able to care for patients with psychotic illness effectively in spite of challenges, furthermore 431 (97.7\%) claimed to have positive attitude towards those diagnosed with psychotic disorders. Also, findings on relationship challenges revealed that 423 (95.9\%) ability to establish adequate relationships with psychotic patients 441 (100.0\%) claimed to have sufficient communication skills, 416 (94.3\%) reported that relationships are vital in mental health nursing care. The study therefore concluded that despite the challenges experienced by the nurses, results indicate that they were still able to adequately care for their patients.

KEYWORDS: Care, Challenges, Experience, Mental Health Nurses, Psychotic Patients. 


\section{INTRODUCTION}

Mental health nurses face daunting and complex challenges within the milieu of mental health care users. Not only are they required to support and care for people hospitalised for treatment of psychosis, but are also expected to manage ward administrative tasks, admit mental health care users, attend meetings, dispense medication and

\section{LITERATURE /THEORETICAL REVIEW}

Mental health nurses reported experiencing feelings of anger and frustration, as well as high levels of burnout in the care of psychotic patients. Whilst mental health nurses indicated that they were suitably trained to deal with psychotic patients, most supported the need for further training (Joubert \& Bhagwan, 2018).

Despite limited research conducted in the field, a few qualitative inquiries undertaken thus far have highlighted the need to consider whether mental health nurses have sufficient knowledge and skill to care and deal with the complexities of psychotic patients. This has been articulated by multiple scholars, who stressed that in order to provide adequate care, nurses require specialized psychiatric nursing knowledge and skills when caring for psychotic patients (Lethoba, Netswera, \& Rankhumiseet, 2012).

Communication can be a struggle for many people with psychotic disorder. Some people don't have the motivation to communicate, while others lack the confidence to say what they really want. They sometimes experience hallucinations, which can affect how and when they communicate. Often, people with psychotic disorders feel cut off from other people, including family, friends and neighbours. (Joubert \& Bhagwan,2018)

Mental Health Nurses will therefore need to help their patient to communicate in order to establish a nurse- patient therapeutic relationship, by giving them enough time to make themselves heard and let them know that you accept them and their disorder. Let them express themselves without interrupting or offering your opinion. Encourage and reassure them if they get upset or appear to be struggling with their emotions.

Also, getting a definite diagnosis of psychotic disorder can be difficult because there are no definitive physical tests. A diagnosis will usually be made by discussing symptoms and taking a medical history. The following are the objective of the study, identify the patient posed challenges, assess the personal challenges, examine the relationship challenge encountered in the care of psychotic patient

\section{Jean Watson's theory of caring}

The Philosophy and Science of Caring has four major concepts: human beings, health, environment/society, and nursing. Jean Watson refers to the human being as "a valued person in and of him or herself to be cared for, respected, nurtured, understood and assisted; in general, a philosophical view of a person as a fully functional integrated self. Human is viewed as greater than and different from the sum of his or her parts." Health is defined as a high level of overall physical, mental, and social functioning; a general adaptive-maintenance level of daily functioning; and the absence of illness, or the presence of efforts leading to the absence of illness. Watson's definition of environment/society addresses the idea that nurses have existed 
in every society, and that a caring attitude is transmitted from generation to generation by the culture of the nursing profession as a unique way of coping with its environment.

The nursing model states that nursing is concerned with promoting health, preventing illness, caring for the sick, and restoring health. It focuses on health promotion, as well as the treatment of diseases. Watson believed that holistic health care is central to the practice of caring in nursing. She defines nursing as "a human science of persons and human health-illness experiences that are mediated by professional, personal, scientific, esthetic and ethical human transactions."

Watson's model helps to reinforce the idea that caring should be central to every decision or action that a nurse makes in practice. By utilizing her theory helps mental health nurses to understand at a deeper level what it truly means to be a nurse. Focusing on aspects like psychosocial care is important in priority and goal setting, particularly in understanding patient lived experiences with psychosis and its impacts and meaning towards her own life. By adopting this model as a framework to assist in psychotic patient care, it emphasizes the importance of addressing emotional needs of psychotic patients. When patients feel cared for and included in their treatment plan, there is more space for increasing their knowledge and understanding of their illness (Torheim \& Kvangarsnes, 2014). Hence, the most important message from Watson's theory is that the science of curing is complementary to the science of caring and therefore the practice of caring is the most central component in nursing.

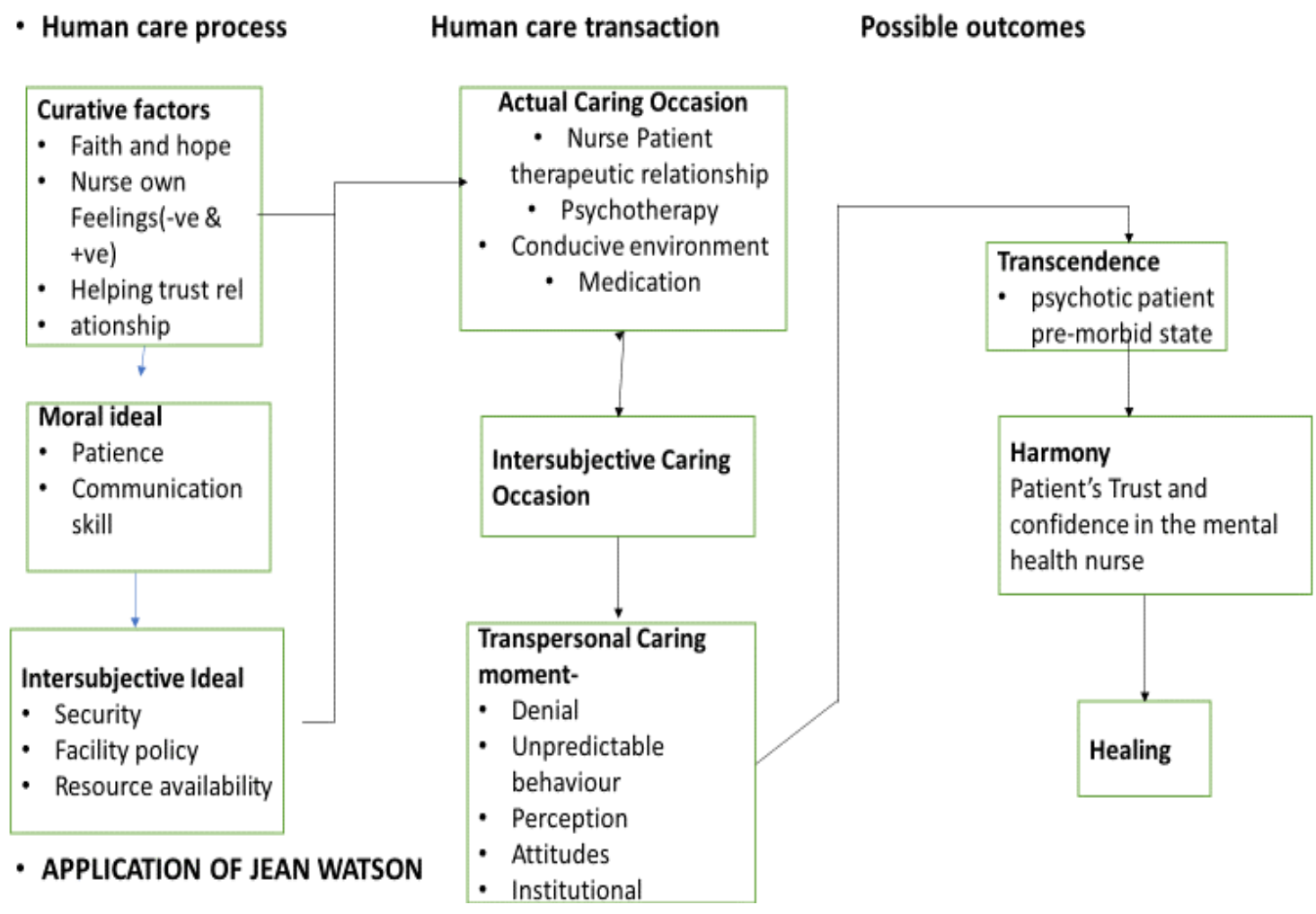

Figure 1.1: Application of jean Watson's theory 


\section{METHODOLOGY}

The study is quantitative research design, specifically adopting the descriptive research method researchers used questionnaire to get data from mental health nurses who are involved in the care of psychotic patients. The readiness of Nurses to participate in the study was the basis for using convenient sampling techniques.

\section{RESULTS/FINDINGS}

Table 4.1: Socio-Demographic Characteristics of Mental Health Nurses

\begin{tabular}{llll}
\hline $\begin{array}{l}\text { Socio-demographic } \\
\text { characteristics }\end{array}$ & & F (\%) \\
\hline 1. & Age of Respondents & $20-29$ & $66(15.0 \%)$ \\
& & $30-39$ & $175(39.7 \%)$ \\
& & $40-49$ & $142(32.2 \%)$ \\
& & 50 years above & $58(13.2 \%)$ \\
2. Gender of Respondents & Male & $150(34.0 \%)$ \\
& & Female & $291(66.0 \%)$ \\
3. Education of Respondents & RN & $90(20.4 \%)$ \\
& & RMN & $166(37.6 \%)$ \\
& & BNSC & $171(38.8 \%)$ \\
4. & Years of Experience & $14(3.2 \%)$ \\
& Respondents & $1-10$ years & $148(33.6 \%)$ \\
& & $11-20$ years & $198(44.9 \%)$ \\
& & $20-30$ years & $64(14.5 \%)$ \\
& & 31 years above & $31(7.0 \%)$ \\
\cline { 3 - 3 } & &
\end{tabular}

Results on the socio-demographics characteristics of mental health nurses revealed that $15 \%$ of the respondents were $20-29$ years, $39.7 \%$ were $30-39$ years, $32.2 \%$ were $40-49$ years and $13.2 \%$ were 50 years above. Also, most of the respondents are female $(66.0 \%)$ and $34.0 \%$ were male. Findings on the education of respondents are revealed as follows; RN (20.4\%), RMN (37.6\%), BNSC (38.8\%) and MSc (3.2\%). Lastly, 33.6\% of the respondents have used $1-10$ years in service, $44.9 \%$ of the respondents have used $11-20$ years, $14.5 \%$ have used 20 30 years and $7.0 \%$ have used 31 years above in service.

Research Question One: What are the patient challenges experienced by mental health nurses in care of patients diagnosed with psychotic disorders? 
Patient Challenges Experienced by Mental Health Nurses in Care of Patients Diagnosed with Psychotic Disorders

\begin{tabular}{|c|c|c|c|c|}
\hline $\mathbf{S} / \mathbf{N}$ & Statements & Yes & No & No Opinion \\
\hline 1 & Does your Patient deny mental illness & $\begin{array}{l}429 \\
(97.3 \%)\end{array}$ & $\begin{array}{l}12 \\
(2.7 \%)\end{array}$ & $0(0.0 \%)$ \\
\hline 2 & $\begin{array}{l}\text { I am are exposed to patients' unpredictable } \\
\text { behavior }\end{array}$ & $\begin{array}{l}441 \\
(100.0 \%)\end{array}$ & $0(0.0 \%)$ & $0(0.0 \%)$ \\
\hline 3 & $\begin{array}{l}\text { Psychotic patient sometimes presents with } \\
\text { increased levels of aggression and violence }\end{array}$ & $\begin{array}{l}441 \\
(100.0 \%)\end{array}$ & $0(0.0 \%)$ & $0(0.0 \%)$ \\
\hline 4 & Patients sometimes refuse medication & $\begin{array}{l}431 \\
(97.7 \%)\end{array}$ & $\begin{array}{l}10 \\
(2.35)\end{array}$ & $0(0.0 \%)$ \\
\hline 6 & There is lack of support from management & $\begin{array}{l}184 \\
(41.7 \%)\end{array}$ & $\begin{array}{l}253 \\
(57.4 \%)\end{array}$ & $4(9.0 \%)$ \\
\hline 7 & $\begin{array}{l}\text { I experience Stress or emotional exhaustion } \\
\text { when caring for suicidal psychotic patient, and } \\
\text { have the ability to balance it }\end{array}$ & $\begin{array}{l}330 \\
(74.8 \%)\end{array}$ & $\begin{array}{l}102 \\
(23.1 \%)\end{array}$ & $9(2.0 \%)$ \\
\hline 8 & $\begin{array}{l}\text { Staff shortage adds to emotional exhaustion and } \\
\text { job dissatisfaction }\end{array}$ & $\begin{array}{l}401 \\
(90.9 \%)\end{array}$ & $\begin{array}{l}36 \\
(8.2 \%)\end{array}$ & $4(0.9 \%)$ \\
\hline 9 & $\begin{array}{l}\text { I have feelings of anger and frustration when } \\
\text { am caring for suicidal psychotic patient }\end{array}$ & $\begin{array}{l}105 \\
(23.8 \%)\end{array}$ & $\begin{array}{l}322 \\
(73.05)\end{array}$ & $14(3.2 \%)$ \\
\hline 10 & $\begin{array}{l}\text { I experience burnout and frustration in the care } \\
\text { of psychotic patient }\end{array}$ & $\begin{array}{l}240 \\
(54.4 \%)\end{array}$ & $\begin{array}{l}172 \\
(39.0 \%)\end{array}$ & $29(6.6 . \%)$ \\
\hline
\end{tabular}

Research Question Two: What is the personal challenge responsible for the challenges faced by nurses in the care of psychotic patients?

Personal Challenges Experienced by Nurses in the Care of Psychotic Patient

\begin{tabular}{|c|c|c|c|c|}
\hline $\mathbf{S} / \mathbf{N}$ & Statements & Yes & No & No Opinion \\
\hline 1 & My Will power is sufficient & $423(95.9 \%)$ & $13(2.9 \%)$ & $5(1.1 \%)$ \\
\hline 2 & $\begin{array}{l}\text { I am able to establish efficient } \\
\text { relationship with psychotic patient }\end{array}$ & $423(95.9 \%)$ & $13(2.9 \%)$ & $5(1.1 \%)$ \\
\hline 3 & I have sufficient communication skills & $441(100.0 \%)$ & $0(0.0 \%)$ & $0(0.0 \%)$ \\
\hline 4 & Do you experience Frustration & $441(100.0 \%)$ & $0(0.0 \%)$ & $0(0.0 \%)$ \\
\hline 5 & Do experience burnout & $441(100.0 \%)$ & $0(0.0 \%)$ & $0(0.0 \%)$ \\
\hline 6 & $\begin{array}{l}\text { Personal intuition is linked to emotional } \\
\text { intelligence }\end{array}$ & $374(84.8 \%)$ & $44(10.0 \%)$ & $23(5.2 \%)$ \\
\hline 7 & $\begin{array}{l}\text { Competence is an integral part of caring } \\
\text { for psychotic patient }\end{array}$ & $437(99.1 \%)$ & $4(0.9 \%)$ & $0(0.0 \%)$ \\
\hline 8 & $\begin{array}{l}\text { I appreciate informal support from } \\
\text { colleague and could easily find someone } \\
\text { with whom I could discuss any personal } \\
\text { difficulties that I might encountered }\end{array}$ & $297(67.3 \%)$ & $74(16.8 \%)$ & $70(15.9 \%)$ \\
\hline
\end{tabular}


9 Informal support lower emotional response

10 Clinical supervision lead to increased self-reflection and competence

11 I am interested in the care and treatment of psychotic illness

12 I am able to care for patients with psychotic illness as effectively with or without the challenges

13 Supervision enables effective care of psychotic patient

15 Caring for psychotic patient requires a great deal of emotional work

16 My behavior and attitude are strong contributor to the continuing discrimination and sigma with which psychotic patient are burdened

18 I have positive attitude towards those diagnosed with psychotic disorders

$\begin{array}{lll}323(73.2 \%) & 60(13.6 \%) & 58(13.2 \%) \\ 356(80.7 \%) & 34(7.7 \%) & 51(11.6 \%) \\ 441(100.0 \%) & 0(0.0 \%) & 0(0.0 \%) \\ 405(91.8 \%) & 36(8.2 \%) & 0(0.0 \%) \\ & & \\ 431(97.7 \%) & 5(1.1 \%) & 5(1.1 \%) \\ & & \\ 251(56.9 \%) & 173 & 17(3.9 \%) \\ & (39.2 \%) & \\ 256(58.0 \%) & 169 & 16(3.6 \%) \\ & (38.3 \%) & \end{array}$

$431(97.7 \%)$ $10(2.3 \%)$

$0(0.0 \%)$

Question 3: Therapeutic Relationship Challenge (TRC)

\begin{tabular}{|c|c|c|c|c|}
\hline $\mathbf{S} / \mathbf{N}$ & Statements & Yes & No & No Opinion \\
\hline 1 & $\begin{array}{l}\text { Communication process between nurses and } \\
\text { patient is interactive and dynamic in nature }\end{array}$ & $\begin{array}{l}383 \\
(86.8 \%)\end{array}$ & $\begin{array}{l}54 \\
(12.2 \%)\end{array}$ & $4(0.9 \%)$ \\
\hline 2 & $\begin{array}{l}\text { Ineffective relationship is usually considered } \\
\text { as a potential obstacle in presenting service to } \\
\text { psychotic patient }\end{array}$ & $\begin{array}{l}376 \\
(85.3 \%)\end{array}$ & $40(9.1 \%)$ & $25(5.7 \%)$ \\
\hline 3 & $\begin{array}{l}\text { Providing nursing care necessitates the nurse } \\
\text { to establish a meaningful relationship with } \\
\text { psychotic patient }\end{array}$ & $\begin{array}{l}269 \\
(61.0 \%)\end{array}$ & $\begin{array}{l}70 \\
(15.9 \%)\end{array}$ & $102(23.1 \%)$ \\
\hline 4 & $\begin{array}{l}\text { Purposeful communication is the with the } \\
\text { main goal of promoting value, interest and } \\
\text { health outcome }\end{array}$ & $\begin{array}{l}273 \\
(61.9 \%)\end{array}$ & $\begin{array}{l}151 \\
34.2 \%\end{array}$ & $17(3.9 \%)$ \\
\hline 5 & $\begin{array}{l}\text { Therapeutic relationship is a rock upon which } \\
\text { mental health nursing is built on }\end{array}$ & $\begin{array}{l}416 \\
(94.3 \%)\end{array}$ & $20(4.5 \%)$ & $5(1.1 \%)$ \\
\hline 6 & $\begin{array}{l}\text { Therapeutic relationship is widely accepted as } \\
\text { the main core of mental health nurse role }\end{array}$ & $\begin{array}{l}369 \\
(83.7 \%)\end{array}$ & $\begin{array}{l}64 \\
(14.5 \%)\end{array}$ & $8(1.8 \%)$ \\
\hline 7 & $\begin{array}{l}\text { The relationship between mental health nurses } \\
\text { and psychotic patient is the most important } \\
\text { element for providing care to psychotic patient }\end{array}$ & $\begin{array}{l}432 \\
(98.0 \%)\end{array}$ & $9(2.0 \%)$ & $0(0.0 \%)$ \\
\hline
\end{tabular}




\begin{tabular}{|c|c|c|c|c|}
\hline 8 & Communication barrier are patient related & $\begin{array}{l}429 \\
(97.3 \%)\end{array}$ & $8(1.8 \%)$ & $4(0.9 \%)$ \\
\hline 9 & $\begin{array}{l}\text { Communication barrier are organizational } \\
\text { related }\end{array}$ & $\begin{array}{l}329 \\
(74.6 \%)\end{array}$ & $\begin{array}{l}74 \\
(16.8 \%)\end{array}$ & $38(8.6 \%)$ \\
\hline 10 & Communication barrier are nurse related & $\begin{array}{l}315 \\
(71.4 \%)\end{array}$ & $\begin{array}{l}107 \\
(24.3 \%)\end{array}$ & $19(4.3 \%)$ \\
\hline 11 & $\begin{array}{l}\text { We have established a good understanding } \\
\text { between us of the kind of changes that would } \\
\text { be good for my patient }\end{array}$ & $\begin{array}{l}388 \\
(88.0 \%)\end{array}$ & $37(8.4 \%)$ & $16(3.6 \%)$ \\
\hline 12 & $\begin{array}{l}\text { My patient believes the way we are working } \\
\text { with her/ his problem is correct }\end{array}$ & $\begin{array}{l}389 \\
(88.2 \%)\end{array}$ & $22(5.0 \%)$ & $30(6.8 \%)$ \\
\hline
\end{tabular}

\section{DISCUSSION}

Findings on the challenges experienced by mental health nurses in care of patients diagnosed with psychotic disorders revealed that patients deny mental illness and that they are exposed to patients' unpredictable behaviour and that psychotic patient sometimes presents with increased levels of aggression and violence respectively which support the study conducted by Joubert and Bhagwan (2018) that stated that psychotic patient deny mental illness, they were also exposed to increased levels of aggression and violence.

In addition, caring for psychotic patients involves managing emotions, emotional expressions and balancing emotional involvement and professional distance, which may be a way of providing good care of patients and oneself. Tofthagen and Fagerstrøm, (2014), which support the report of this study that revealed that respondents experienced stress and or emotional exhaustion, but have the ability to balance the emotional involvement.

Report on personal challenge revealed that respondents have positive attitude towards those diagnosed with psychotic disorders which is accordance with the study carried out by (Ngako, Rensburg \& Matabogeet, 2012) that stated that despite the roles played by mental health nurses are multifaceted and demand working positively with patients who are diagnosed with psychotic disorders. In addition, factors such as insufficient staff and increased workloads add Do experience burnout to the stressors in acute psychiatric settings

The study further revealed that mental health nurses experience burnout which supports the study carried out by (Joubert \& Bhagwan, 2018) that stated that mental health nurses reported experiencing feelings of anger and frustration, as well as high levels of burnout in the care of psychotic patients. While mental health nurses indicated that they were suitably trained to deal with psychotic patients, most supported the need for further training

The present study revealed that respondent appreciate informal support from colleague and could easily find someone with whom they could discuss any personal difficulties that they might encountered and it was also reported that Informal support lower emotional response which is in support of the work of Cutcliffe and Stevenson, 2018, study that revealed that caring for psychotic patients is demanding and nurses need informal and formal support CastelliDransart, 2014 found that nurses that had received sufficient support reported low emotional response and traumatic impact. 
The study revealed that Personal intuition is linked to emotional intelligence which support the study of Tofthagen and Fagerstrøm, (2014) study, that opined that mental health nurses were able to observe signs of self-harm and sometimes experienced a sense of intuition regarding a patient's impending self-harm and also the study conducted by Chesla (2019), 'expert nurses' are able to read a patient/situation and respond instantaneously, claiming that there are intuitive links between noticing significant aspects and ways of responding to them. It has been suggested that intuition is involved in experienced mental health nurses' suicide assessments (Aflague\&Ferszt, 2010), and that the intuition is linked to formal and tacit knowledge (Welsh \& Lyons, 2011). Whereas Akerjordet and Severinsson (2014) stated that intuition is a part of mental health nurses' emotional intelligence, Klein (2013) described it as a skill built up through repeated experiences in which one learns to recognize a set of cues

The study also revealed that supervision can help reduce the level of burn out which supports the study that supervision might enable the nurses to continue caring for psychotic patients and contribute to lower levels of burnout (Sherring \& Knight, 2019).

Considering the adverse effects burnout may have on professionals' mental health and on quality of care (Maslach \& Jackson, 2011, Sherring \& Knight, 2019), study suggests that there should be more focus on formal support systems for mental health nurses.

This study revealed that mental has positive attitude towards their patient, which does not support the study of Wahl, (2019) that reported that people with psychotic disorders and their families often include instances of disrespectful treatment and negative attitudes expressed by the mental health nurses they encounter Findings such as these have led researchers and advocates to suggest that the behavior and attitudes of mental health nurses may be strong contributors to the continuing discrimination and stigma with which people with mental illness are burdened (Sartorius, 2012).

The study revealed that respondents have a positive attitude towards their patient, which is in line with the study conducted that states that numerous studies provided evidence that mental health nurses have overall positive attitudes towards those diagnosed with psychotic disorders or, at least, attitudes that are more positive than those of the general population. Kingdon, Sharma, and Hart (2014)

Study on relationship challenge revealed that respondents have sufficient communication skills and also reported that purposeful communication is the main goal of promoting value, interest and health outcome which buttress the study that revealed that communication can be a struggle for many people with psychotic disorder. Some patients don't have the motivation to communicate, while others lack the confidence to say what they really want. They sometimes experience hallucinations, which can affect how and when they communicate. Often, people with psychotic disorders feel cut off from other people, including family, friends and neighbours, (Joubert \& Bhagwan,2018) and also is in line with the study that stated that purposed communication is with the main goal of promoting the values, interests, and health outcomes of the patients (Porr, 2009). Many theorists in mental health nursing believe that the therapeutic relationship is a 'rock', upon which mental health nursing is built (Scanlon, 2006) and it is widely accepted as the main core of the mental health nurse's role. According to Theodoridou, Schlatter, Ajdacic, Rossler, and Jager (2012), the relationship between mental health nurses and psychotic patients is the most important element for providing care to psychotic patients. Although creating a therapeutic relationship with patients is a central goal 
of mental health nursing (Thomas, Shattell, \& Martin 2002), The communicative process between nurse and patient is of an interactive and dynamic nature (Hall, 2003), which is affected by different factors, such as social, cultural, moral, economic, logical, and technological trends. The inefficient relationship is usually considered as a potential obstacle in presenting services in the healthcare environment (Reynolds \& Scott, 2000); and to establish an effective relationship, primarily the restraining challenges in the nurse-patient relationship must be addressed (Tuohy, 2003). Lack of time was declared as the main concern of nurses for establishing relationships with the patients. Shortage of man-power (nurses) and the large number of patients are among the most fundamental problems that mental health nurses encounter within the care system (Anoosheh et al., 2019). The results of Park and Song (2015) showed that overwork is one of the main relationship barriers for nurses, affecting both the quality and quantity of communication between nurses and patients.

In conclusion, Generalization of the study should be done with caution as some of the mental health nurses' views might not be reported due to lack of access to the government hospital due to financial cost and time factor.

The research could serve as a basis for further research in the area of understanding the relationship between socio-demographic factors and the relationship with the care of psychotic patients.

\section{REFERENCES}

Adebowale T.O, Ogunlesi A.O. Beliefs and knowledge about aetiology of mental illness among Nigerian psychiatric patients and their relatives. African Journal of Medicine and Medical Science. 2019;28:35-41.

Aghabarary, M., Mohammadi, E., \& Varvani-Farahani, A. (2010). Barriers to application of communicative skills by nurses in nurse-patient in-teraction: nurses and patients' perspective. Iran Nursing Journal,22(61),19-31.

Anoosheh, M., Zarkhah, S., Faghihzadeh, S., \& Vaismoradi, M. (2009).Nurse-patient communication barriers in Iranian nursing.International Nurs-ing Review, 56, 243-249.

Austin, W., Lemermeyer, G., Goldberg, L., Bergum, V., \& Johnson, M. S.(2005). Moral distress in healthcare practice: the situation of nurses.HealthCare Ethics Committee Forum,17(1), 33-48

Baldessarini R.J, Tarazi F.I: Drugs treatment of psychiatric disorders, psychosis and mania. In Goodman and Gilman's pharmacological basis of therapeutics (Eds) Hardman JG,Limbird I.E. MiGraw -Hill, New York. 2011;485- 520.

Baraz Pordanjani, S. H., Shariati Abd, A., Alijani Renani, H., \& MoeinMousavi, S. (2011). Assessing barriers of nurse-patient's effective com-munication in educational hospitals of Ahwaz.Nursing Research,5(16),45-52.

Barker, P. (1998). The future of the theory of interpersonal relation? A personal reflection on Peplau's legacy.Journal of Psychiatric and Mental HealthNursing,5, 213-220.

Bonnie, P. \& Hagerty, K. (2003). Reconceptualizing the nurse-patient relationship Journal of Nursing Scholarship,35(2), 145-150

Caris-Verhallen, W. M., de Gruijter, I. M., Kerkstra, A., \& Bensing, J. M.(1999). Factors related to nurse communication with elderly people Journal of Advanced Nursing,30, 1106-1117. 
Cleary, M. \& Edwards, C. (1999). Something always comes up: nurse-patient interaction in an acute psychiatric setting.Journal of Psychiatric and MentalHealth Nursing,6, 469477.

Cleary, M., Edwards, C., \& Meehan, M. (1999). Factors influencing nurse-patient interaction in the acute psychiatric setting: an exploratory in-vestigation.Australian and New Zealand Journal of Mental Health Nursing,8(3), 109-116.

Cleary, M., Hunt, G. E., Horsfall, J., \& Deacon, M. (2012). Nurse-patient interaction in acute adult inpatient mental health units: a review and synthesis of qualitative studies.Issues in Mental Health Nursing,33, 66-79.

Currid, T. (2009). Experiences of stress among nurses in acute mental health settings. Nursing Standard,23(44), 40-46

Davis K.L, Kahn R.S, Grant K.O, Davidson M. Dopamine in schizophrenia: A new review and conceptualization. American Journal of Psychiatry. 2010;148:1474- 1486.

Elo, S. \& Kyngas, H. (2008). The qualitative content analysis process. Journal Of Advanced Nursing,62(1), 107-115.

Fakhr-Movahedi, A., Salsali, M., Negarandeh, R., \& Rahnavard, Z. (2011). [Exploring contextual factors of the nurse-patient relationship: A qualitative study.] Koomesh,13(1), 23-34.

Falahi, M., Maddah, S., Shamloo, S., Abedi, H. A., \& Babaei, G. (2003). [Designing a multidimensional psychiatric rehabilitation nursing model inthe care of schizophrenic patients.]Teb Va Tazkieh,46, 34-45.

Fleischer, S., Berg, A., Zimmermann, M., Wüuste, K., \& Behrens, J. (2009). Nurse-patient interaction and communication: A systematic literature review.Journal of Public Health, 17, 339-353.

Graneheim, U. H. \& Lundman, B. (2004). Qualitative content analysis in nurs-ing research: Concepts, procedures and measures to achieve trustworthiness.Nurse Education Today, 24, 105-112.

Gunasekara, T. Pentland, T. Rodgers, S. Patterson What makes an excellent mental health nurse? A pragmatic inquiry initiated and conducted by people with lived experience of service useInternational Journal of Mental HealthNursing, 23 (2) (2014),

pp. 101

Hagerty, B. M. \& Patusky, K. L. (2003). Reconceptualizing the nurse-patient relationship.Journal of Nursing Scholarship,35(2), 145-150.

Hall, J. A. (2003). Some observations on provider-patient communication research. Patient Education and Counseling,50, 9-12.

Holloway, I. \& Wheeler, S. (2002).Qualitative Research in Nursing.Oxford:Blackwell.INO. (2011). Report. Iranian Nursing Organization, Tehran. [In Persian].

K. Ngako, E.S.J. van Rensburg, S.M.L. MatabogePsychiatric nurse practitioners experiences of working with mental health care users presenting with acutesymptomsCurationis, 35 (1) (2012),pp. 1-9 available: <http://search.proquest.com.dutlib.dut.ac.za> Accessed 25 August 20

K.G. Lethoba, F.G. Netswera, E. RankhumiseHow professional nurses in a general hospital setting perceive mentally ill patientsCurationis, 29 (4) (2016), pp. 4-11

L. Uys, L. Middleton (Eds.), Mental health nursing: A South African perspective $\left(5^{\text {th }}\right.$ ed.)., Juta and Company Ltd., Cape Town (2010) 